This is the author's penultimate, peer-reviewed, post-print manuscript as accepted for publication. The publisher-formatted PDF may be available through the journal web site or, your college and university library.

\title{
The search for authentic practice across the disciplinary divide
}

Greg Knotts, Lynette Henderson, Ronald A. Davidson, and John D. Swain

\section{Manuscript Citation}

The following (APA) citation may be used to reference this manuscript:

Davidson, R.A., Henderson, L., Knotts, G., Swain, J.D., (2009). The search for authentic practice across the disciplinary divide. Retrieved from http://scholarworks.csun.edu

\section{Published Version Information}

Citation: Davidson, R.A., Henderson, L., Knotts, G., Swain, J.D., (2009 The search for authentic practice across the disciplinary divide. College Teaching, 57(4), 188-96.

Copyright: Copyright $\odot$ Taylor \& Francis Group, LLC

Digital Object Identifier (DOI): 10.1080/87567550903218562

Publisher URL: http://www.tandfonline.com/doi/abs/10.1080/87567550903218562 


\section{THE SEARCH FOR}

AUTHENTIC

PRACTICE ACROSS THE

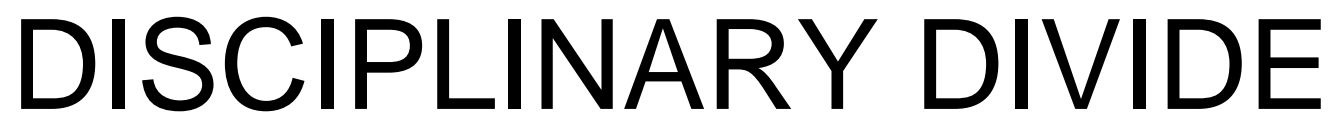

Greg Knotts, Lynette Henderson, Ronald A. Davidson, and John D. Swain 
Abstract. This article describes the self-reflexive investigation of four first-year faculty at a comprehensive state university in Southern California. In professional development efforts to identify best practice, each of us explored and evaluated our teaching philosophies, strategies, and roles as both educators and researchers in the context of an institution for higher education. Issues related to our search for a personal and interdisciplinary definition of authentic teaching and learning were first suggested to us by the writing of Bain (2004), in his discussion of the "natural critical learning environment" (18). We researched other authors on this topic and conducted empirical investigations, eventually identifying four elements of authentic teaching and learning that cross disciplinary boundaries. These elements may be used as a model for authentically engaged teaching practices that can uphold standards while revitalizing teaching and learning in the contemporary college classroom. We also offer a collaborative model of professional development that should be used to enhance authentic best practices across the dis-

ciplinary divide. (AQ: Abstract needs to be under 100 words and please add 3-5 keywords)

\section{Keywords:}

$\mathrm{T}$ As part of our orientation to the university, each new faculty member was given a copy of education researcher Ken Bain's What the Best College Teachers Do (2004). The faculty development department also offered to facilitate a semester-long book group, where we could discuss the content of

\section{AQ: Please addd a brief biosketch for this space.}

the character of what we sought in terms of assessment, instructional content, and interaction with students.

In seeking our own definition of "authentic", "real", and "appropriate", we also ventured beyond the assumption that an institution of higher education is intrinsically valuable, to find additional validation for the university venue. John Dewey wrote (1944) that education occurs in many places in society, not just inside classrooms. Clubs, churches, the media, social and civic groups, and political parties, for example, all contribute to what we know about the world. These forums, however, offer incommensurate and fragmented forms of knowledge. According to Dewey, it is the special role of the formal educational system to integrate knowledge and provide a stable learning environment. With that in mind, we compiled four elements of authenticity within this venue, applicable to both teacher and student: (1) being present in the classroom; (2) awareness and utilization of context; (3) active engagement; and (4) and ownership of education for student-centered learning.

Defining authenticity with these four elements helped focus our efforts in reflecting on our own practice, as well as offered a lens when observing each other's teaching. Various authors have elaborated on similar topics in a collection of essays edited by Cranton titled

Authenticity in Teaching (2006). "Being present in the classroom" refers to our 
efforts to be mindful that when we are in the classroom we must not allow ourselves to be distracted by the task of balancing teaching, committee work, scholarly pursuits and our personal lives (Dirkx 2006; Hunt 2006; Kornelson 2006). "Awareness and utilization of context" refers to our efforts to prioritize and use the experiences, life histories, and personalities of the students in the room, in addition to the specific content we might be addressing in a given class session" (Lin 2006). This element, while seemingly straightforward, cannot be underestimated in helping our students find relevancy as they engage with the content; i.e., "meet them where they are." Frego (2006) addresses the roles and needs of teachers and students as they navigate their relationships to each other, the course content and their ability to learn. These issues relate to achievement of our third and fourth elements. The third element, "active engagement," speaks to our attempt to get students actively engaged in their own learning, as opposed to being passive recipients waiting to be filled with information. The fourth element is perhaps the most elusive. "Ownership of education for student-centered learning" addresses our efforts to get students to claim investment in their education. Brookfield (2006) discusses issues of power in the classroom, which relates to our final statement about authenticity: while we all come prepared with syllabi, readily direct and facilitate the learning environment - to be truly authentic, student voice must be an active component to the learning.

\section{First-Year Faculty and the Collaborative Model}

In this section we present the collaborative model developed by the book group and the challenges that emerged in our collective search for authenticity. This model has five qualities (figure 1).

Collaboration. Collaboration is a central component of the model, around which the other elements revolve. One meaning of collaborative is to co-operate treasonously with an enemy. Our group has no enemy, but, as a collection of relatively low-status newcomers in a hierarchical institution, it does perceive an inevitable "other" in the form of a vaguely-defined "the administration" or "the university."
As first-year faculty we must not only deal with the anxiety-producing terms of probationary employment and the knowledge that our performance in teaching, research, and service is being scrupulously monitored by agents of this "other", but also our lack of familiarity with a wide range of unofficial, cultural, and social norms specific to our campus community. Thus at our first book group meetings we were collaborators with the university, passively following the agenda set by the Office for Faculty Development. We soon found, however, that under the leadership of the Director, this particular agent of the university provided both the institutional space and encouragement for us to transform the nature of our collaboration. We took greater control over the process of our professional development and became collaborative as a group pursuing its own, university-sanctioned, goals - a practice supported by the participants in Katz and Henry's (1988) descriptions of a similar collaboration. This was an empowering evolution of the book group, and it occurred through shared decision-making and leadership. For example, the original format of the group called for four meetings, but we chose to cancel the last one and instead observe each other's classroom teaching. This in turn spurred us to share our results at one and then two and three conferences and, ultimately, to write this article. We have come to define working collaboratively as working by choice, with each other rather than for anybody else.

Self-Reflection. Self-reflexivity may be common enough in academia, but it is usually practiced within the rigidly circumscribed boundaries of one's own academic discipline. This is not, of course, entirely negative. Scholarship on effective teaching suggests that the best teachers are deeply embedded in their particular disciplines. The concept of pedagogic content knowledge (PCK) entails having an intimate familiarity with the internal dynamics of a discipline, knowing the debates and controversies and particularities of method and being able to communicate these to students (Wineburg 2001). Thus it is useful to observe the teaching techniques of one's departmental colleagues and to refine one's teaching in light of insular models and criteria. Yet we found that "crossing the disciplinary divide" to observe teaching in other departments can be extremely helpful. Not only can this illuminate interdisciplinary connections and assist in efforts to provide a cohesive education to our students (see Huber et al. 2007), but it can also promote self-reflexivity within our respective disciplines. Tired assumptions that go unchallenged in the micro-culture of our own departments can be seen afresh; new ideas can emerge. "Knowledge about teaching is emancipatory," wrote Cranton and King (2003, 31). Incorporating critical reflection on our own practice while reflecting on the practice of others has assisted in breaking up adopted and habitual frameworks (Brookfield 2002; Mezirow 1997). By forcing us to reflect on teaching at a meta-level it has also promoted the ideal of achieving an equitable balance between teaching and scholarship (Huber 2001). For example, the book group's geographer observed the theater historian's class. The (literal) staging of the classroom as a theater for a series of student performances led the geographer to reflect on how to use drama, and the manipulation of classroom furniture and other "props" to put students, rather than the instructor, more "on stage," thus more deeply invested in the process of their education. This theatrical approach is novel in the geography department and promises to engage geography students in a new and meaningful way. In short, exposing oneself to teaching practices in a different discipline can promote self-reflexivity and sharpen one's focus on one's own performance.

Reciprocity. Classroom evaluations in our university are normally conducted by tenured faculty members who observe 20-30 minutes of a class session, and then write up a report. As a uni-directional and hierarchical process that is tied to a system of official sanctions, this replicates the advisor-advisee relationship typical of that between students and their advisors. This is a model that many educators criticize as overly hierarchical even in that context (Kartje 1996; Quinlan 1998; TWIG 1996). In our model, peers from different departments observe each other, as much for their own benefit as for the observee's (Katz and Henry 1988). We have therefore become co-mentors in a non-threatening and equitable for- 
mat, recognizing each other equally as sources of ideas and seeking to be mutually transformative (Cranton and King 2003; Kartje 1996; Mezirow 1997). As observers of classroom teaching across the disciplinary divide we drew less from our disciplinary expertise and more from our creativity as scholars to interpret, assess, and draw lessons from teaching practices in diverse settings. We find this fully in line with Paulsen and Feldman's call for an enlarged view of scholarship that encompasses teaching (and service) under its rubric (1995). As an example, the book group's Teacher Education assistant professor observed the Art Education assistant professor's class and gained insight into how to incorporate reflection into in-class activities without losing sight of the assignment's immediate goals.

Partial and positional truth. Our classroom observations and ongoing dialogue has served to reinforce our shared identities as new faculty and our individual identities as defined by our department affiliations.

Cross-Cultural Perspectives. As our group becomes collectively acculturated into the wider university, the individual members also settle ever deeper into their separate niches defined by discipline-specific teaching and learning. Through our discussions and shared experiences we have become more aware and in control of these simultaneous "push-pull" influences on our professional identities.

This collaboration, an investment in ourselves as professionals, has not been without challenge. Our search for authenticity, for what was best for each of us within our own disciplines and individual teaching practices, helped uncover similarities and differences within our own teaching styles and pedagogies. In the following sections, each of us reflects on these issues from the authentic standpoint of our individual disciplines: teacher education, art education, geography, and theater history. We also include reflections on our observations of each other's teaching practice as a way of providing interdisciplinary relevance to our own discipline-specific definitions of authenticity. To the reader in search of his or her own best practices, we offer commonalities in our concluding section that can function as both theory and praxis for multiple disciplines.

\section{Authenticity in Teacher Education}

"What do you do when a student pukes?" I ask my teacher candidates on the first night of class. This vivid intrusion into the sensibilities of students helps make the theoretic classroom as real-world and authentic as possible. Authenticity in teacher education can best be described as creating for stu- more those candidates value their own learning activities and experiences (Bird and Rosaen 2005). In my own 'theoretical' classroom, I often have equal numbers of students who are teachers at various types of schools, who are presently doing their first or second semester of student teaching, and students who have not been in a $\mathrm{K}-5$ classroom since they were in elementary school themselves. In so many ways this resembles the challenges facing $\mathrm{K}-5$ teachers who find themselves in classrooms with a disparate group of dents audience-driven tasks that resemble real-world challenges (Stader and HillWinstead 2002). As I come prepared to be present in the classroom, the first element in our definition of authenticity, I am keenly aware of this need that students have to discuss, relive, or shed light on, real-world experiences. Students of education, future teachers, want practical, implementable strategies for every possible circumstance and contingency that may arise in their future classrooms. In order to be authentic, teacher education courses must be culturally relevant, so that future teachers can individually develop their competence, confidence, and readiness (Gallavan 2005). In order to maintain this relevancy, every class session must not only meet the standards and desired outcomes of the course, but must also strive to respond to the situations that do-or might in the futurearise in their own K-5 classrooms. This most aligns to the second component of our own definition of authenticity, awareness and utilization of context.

This question of context cannot be underestimated. The more that teacher candidates perceive their own learning to be centered around authentic tasks, the learners and varied levels of knowledge and experience. It is important to raise the consciousness of students and make them aware that they are learning in the same type of varied context in which they are, or will be, teaching. In order to be an effective teacher educator, I must honor these varied experiences of my own students and help them to find relevance for their own teaching. The most successful teacher education courses help to make sense of their variety of learners by offering students meaningful learning experiences, reflective analysis, and the opportunity to develop a personal theory of teaching and learning (Dangel and Guyton 2003) (AQ: Says Daniel in the references. Which is correct?).

In order to provide these requisite components for efficacy, I create a variety of constructivist activities and develop rubrics with students so that they help to create ownership of their learning, the fourth element of our definition of authenticity (Stader and Hill-Winstead 2002; Williams et al. 2003). I differentiate assignments to meet the needs of students in their varied contexts. For instance, one assignment that responds to the "meaningful learning experience" 
component of a successful classroom is to create an example of center-based instruction, where $\mathrm{K}-5$ students can autonomously direct their own learning in a designated portion of the classroom. Candidates already teaching can create a real-life learning center that must include a learning objective and self-guided tasks for students to accomplish in order to extend and supplement direct instruction. Afterwards, the student submits photographs with written descriptions of how the center was implemented. Candidates not already teaching must design, create, and submit the actual learning center in class. In this way, students can better find relevancy and authenticity for their own teaching practice.

In response to the "reflective analysis" component of Dangel and Guyton's (2003) successful classroom, I implement a constructivist protocol four times throughout the semester. Using the protocol, I question students on my own teaching effectiveness, as well as their contributions to the class. For instance, in week four of class, I ask students to list at least five qualities in my teaching that have best helped to scaffold their learning. They then meet in pairs to agree on five qualities, then in groups of four to agree on five qualities, and then as a class we agree on what have been the five most effective qualities of my teaching. This process models for students a way for them to become actively engaged in the classroom, the third element of our authenticity definition, and to use reflection, student voice, and self-assessment for their own future classrooms. This echoes an activity I observed in my colleagues's Art Education class. For instance, during my observation of her class, she had students describe their art projects in ways that were meaningful to them, but still related to the assignment's goals. Creating art, by nature, is an act of both "thinking" and "doing", however she extended the doing part of the learning activity to also include reflection, modeling for me how to include that component effectively in instruction.

There are many applications of this strategy. For instance, using the same constructivist protocol as a strategy, students can develop a personal theory of teaching and learning; i.e., ask themselves what they believe to be necessary components of a successful classroom, meet in pairs, small groups, and then as a class, create a list of necessary components. Teacher education programs must model for candidates how to become reflective practitioners, who consider their own practice, the learning outcomes of their students, and how they engage in their schools as professionals. These kinds of real-world challenges continue to provide authentic learning opportunities for candidates in teacher education.

\section{Authenticity and Art Education}

Discipline-appropriate practices that I am able to name "authentic" incorporate both Cranton's (2006) and Mezirow's (1997) ideas about transformative learning. I have observed that this experience can be achieved by both teacher and students through utilization of self-reflective activities, including examination of "frames of reference" (Mezirow 1997, 5). In addition, retaining an element of immediacy, in both content and classroom interaction, can provide further support to the incorporation of context and the two closely connected elements: being present (fully focused in the moment), and active engagement. Immediacy relates to both teachers' and students' efforts to construct and reconstruct what is already known with each new educational encounter. The following paragraphs describe one way in which I negotiated the four elements of authenticity for myself and for my students.

Contrary to the romantic notion that opinions on aesthetics and meaning of artworks are purely personal and come from some vague internal source, analysis and judgment of art images and objects are a socially-constructed practice and is influenced by a number of external factors, including mass media, global consumerism, and marketing of culture (Desai 2005). These influences are often more powerful than the occasional art education experience, which traditionally presumes that cultures are intact and identifiable; today's cultural artifacts, however, are now often outsourced or even pirated. Understanding images and objects is especially important in our contemporary world of global sources of information, visual culture of surveillances (Sweeney
2006), hyperaesthetics (Taylor 2002), and daily interaction with computer data, hypertext, images and sound (Duncum 2004). Such understanding can facilitate not only more informed choices, but can also assist us to "locate" ourselves within the global cultural arena.

During one classroom activity in my course on cross- and multi-cultural art education, we analyzed artworks that I had encountered unexpectedly out in the community only a few days earlier. I had viewed an exhibition of beautifully executed photographs of non-Western and no-technological cultures, by an individual artist from the United States, at a local art center. The titles of these works, however, appeared to me to negatively objectify the people and activities depicted, such as those accompanying breast-feeding twin babies, women sifting through a pile of rice with a basket, or a man watering a garden with cans tied to a shoulder-harnessed pole. I decided to bring my own photographs of this exhibition to class, ask my students what they thought, and see what might come up as issues for discussion.

I presented the images first, then beginning with a "reverse" inquiry approach, I asked the two questions: "What do you think?" then "What does our perception of them say about us?" The students agreed on the high technical quality but felt that the titles did not do justice to the images; in response, the tendency was to simply ignore or bypass them so they could experience the pictures. I felt the titles provided a unique opportunity, however, to deconstruct both the artist's conceptual and visual presentation of "others" in his photographs, as well as investigate how the 'conceptual framing' of artwork can influence viewers. To get past students' initial responses I asked the following contextual questions, some of which I posed that day during discussion, and some the following class period:

- Presentation: What is the nature of the venue for exhibition? Who are the anticipated viewers? What information does the sponsor provide? How are the images physically "framed"?

- Artist: What are his or her stated intentions, if any? How do the artist's titles affect how you interpret the images? 
Are the titles and images in agreement?

- Language: What language is used to describe the image or object? Is the Western version of the elements and principles of design in use, and how does that relate to the culture depicted? Can English appropriately describe what is in the image or object? How might the meaning change with a change in language?

Thus, the immediate responses of the students helped generate a set of questions that I utilized to amplify this impromptu lesson. Thinking about it further, I realized the notion of inquiry can be expanded beyond the asking of specific questions, towards the concept of problematizing knowledge_-viewing knowledge as a selfreflexive process of questioning (wondering) and answering (responding) - a cyclical process of "search" and "arrival." I developed another, broader, set of questions that helped review and critique the goals for the entire course:

- What is the purpose of studying a particular culture, i.e., what is gained?

- What are some differences between the methods we use in this class to learn about "other" cultures, and what might we do in a "traditional" Western studio art class? How might the "traditional" activities and goals act as a "filter" for our understanding? What "filters" (or lenses) do we utilize in this class?

- How have contemporary global marketing practices and communications influenced your understanding of "culture?"

- How might the way in which museums exhibit and explain art and artifacts from "other" cultures define the way we view others?

-Is it possible to avoid objectifying the subject of study in order to study it? How might you do that?

- When we learn about "other" cultures, what can we say we really "know" about them?

At the end of such a self-reflexive cycle, we then account for new facts and understandings, while maintaining awareness that what we "know" is highly useful but as a construction, incomplete, and therefore open to future engagement. Such openness is in alignment with authentic teaching and learning in terms of allowing context and active, in-the-moment investigation to integrate with the students' base of prior knowledge.

My art education classes are comprised of approximately 20-30 students; it is not difficult to facilitate active individual engagement with a group that size. In visiting one of Professor Davidson's geography lecture courses, I noted how the large size of the class potentially hindered interaction and individual engagement. His orchestrated presentation of provocative discussion questions to small groups, however, engaged even those students in the distant rear, and, no doubt, many who might otherwise refrain from speaking up in the larger group. The smaller groups then reported out to the larger audience for everyone's benefit. This sounds like a simple and common practice, but is one that may be under-utilized due to time constraints, amount of material to cover, or other similar concerns. My observation of happily-alert art education and geography students, however, confirms my belief in the value of formulating a process of inquiry and allowing for interaction (even in the form of occasional "way stations") over a semester, as one of the foundations of successful authentic practice.

\section{Authenticity and Geography}

As a geographer, I am professionally prone to recognizing that authentic teaching practices are shaped by place. How so? Let me illustrate with my own situation. On the first day of class each semester, I ask my students to stand around the room in spaces representing the regions in which their grandparents lived-the Middle East here, Latin America there, and so on. When everybody gets in position we discover that the space reserved for "California," at the front of the room, has at most one or two students - the fewest of any region represented. Yet my university is not just anyplace in California but in Los Angeles County, where 1/7 of all new immigrants to the United States settle (Clarke 1999). I teach in one of the most diverse places in the world. Thus my students have different cultural backgrounds, first languages, personal experiences and senses of place. What does "authentic" teaching mean in this context? Is there one "authentic" way to teach all of my students? In this section I discuss how the ideas of authenticity settled upon by our book group can provide answers to these questions in the context of geography education.

Inspiration comes from the work of the American pragmatist philosopher John Dewey. Dewey formulated his philosophy of education in the interwar period, another time of high immigration rates to the U.S. Against the rising tide of antiimmigrant sentiments that would culminate in the door-shutting Immigration Act of 1924, Dewey argued that positive tolerance of immigrants' cultural distinctiveness was vital to American democracy (see Eisele 1975, 70).

Recent research suggests that immigrants' distinctiveness is also important for education (Allen 2006). This research suggests that children of immigrants often do better in school when they identify themselves as members of a particular immigrant community. Studies conducted in Miami and San Diego suggest that second-generation immigrants retain their parents' high motivation to "better" their situation, and this is reflected in their having lower dropout rates than the overall student population (Allen 2006). The edge that second-generation immigrant students have tends to fade in the third generation, when descendants of immigrants lose their immigrant identity and begin to see themselves as part of a generalized minority American group.

The children of immigrants thus seem to have an educational advantage. But can their experience as immigrants be harnessed to benefit all students in the geography classroom? Dewey's writings suggest how such harnessing is possible. Dewey (1944) argued that the subject of geography (as well as history) broadened students by enlarging the meaning of their ordinary experiences. Thus by placing "our own doings in their time and space connections, our doings gain in significant content" (208). In order to broaden, however, teachers must introduce history and geography with lessons about immediate pasts and local places which are connected to students' lives. Dewey wrote that " $[\mathrm{W}]$ hen the familiar fences that mark 
the limits of the village proprietors are signs that introduce an understanding of the boundaries of great nations, even fences are lighted with meaning" (212). ${ }^{1}$ This metaphoric strategy also reveals how all four of the book group's definitions of authenticity are related: by strategically extrapolating from the local context (via awareness and utilization of context) instructors can enhance student interest in geography (facilitating active engagement) and highlight connections that reveal how and why geography matters (inviting students to claim ownership of their education). Successfully achieving these aims requires me to be fully present in the classroom, focused on the task at hand.

In a globalized metropolis, a difficulty in this approach lies in identifying the local or "home geographies" of many of our students. For recently arrived immigrants, home can be a hybrid of local and distant places. Our students' identities evolve from historic-geographic contexts that link multiple worlds together. If authentic teaching implies bringing the "real world" into the classroom, as the teacher educator argues above, then students' themselves are sources of complex authentic geographies. A key moment in teaching is hence the transforming of raw material from students' background experiences into meaningful classroom discussions and assignments. By exposing me to the creative pedagogic practices of my colleagues in diverse departments, the book group has given me a whole new set of reference points for effecting the transformation. For example, after attending my colleague Professor Swain's theater history class, in which students stood before projected PowerPoint images of theater stages they had designed, I decided to have my World Geography students create similar theatrical settings to motivate them to "act" (or express) their geographic identities in short presentations. This is but one example, each of my book group colleagues have given me new ways to approach the riddle of making sense of "home" geography in Los Angeles.

\section{Authenticity and Theater History}

The elements our group define as "authentic" teaching, being present, awareness of context, active engagement, and student centered learning, echo centuries of expectations about theater performance. Theater practitioners worldwide, and throughout history, such as Aristotle, Bharata, Zeami, and Shakespeare called for the authentic on stage. Modern day theater artists and scholars such as Elin Diamond, Richard Schechner, Philip Auslander, and Uta Hagen demand and theorize about authenticity and truth in performance and actor/spectator interaction, each of them utilizing, to different extents, all four elements of our authentic teaching.

For example, Diamond's feminist deconstruction of Aristotle's conception of mimesis centers on the construction of subjecthood and how a narrative of identity may produce a fantasy of being fully present (148). In acting and teaching terms, that "fantasy" allows the actor or teacher to put other concerns aside and bring all their mental energies onto the stage or into the classroom, and by being present, make the performance or the lesson most meaningful for the spectator or the student. Schechner writes of the different nature and reception of authenticity experienced and expressed in various cultures, such as Lawrence Olivier playing Othello or a Balinese dancer in a trance (38). Their particular culture's constructed concept of performance makes what the actor or shaman does meaningful for the spectator, just as an instructor's awareness of the social and educational context of the subject matter makes it meaningful for the pupil. Auslander draws on Richard Meltzer and Lawrence Grossberg to theorize on how our mediatized age has come to value "authentic inauthenticity" (90). Use of electronic media are just one of the expectations theater spectators and classroom students have for (Auslander's term) "liveness" that makes the stage or classroom event "real," and centered on what the students know and need for learning.

Actress and teacher Uta Hagen wrote about her training and development as an actor at the Royal Academy of Dramatic Art in London where she, "loved the notion of studying for my profession with classmates who shared my dreams even though the actual training was poor. At best it was academic" (xviii; emphasis added). Her early memories as a profes- sional actor echo that pejorative "academic." She wrote, "I became enmeshed in a professionalism that is based on external shapes and styles, tricks used to shape a performance almost at the first rehearsal. This resulted in the kind of acceptable clichés I had already rejected when I saw them on stage as a child" (xx). Avoiding acting clichés is active engagement in the moment of the stage action. Confusion can arise because in stage lingo, "being present in the moment" is not about leaving personal concerns off-stage, as we here define "being present" (although they are connected). That stage jargon means to be able to hear and respond to immediate stimulus provided by events of the action, fellow actors, and spectators, in the manner in which we are defining active engagement. As student or teacher, teaching and learning clichés, i.e., disengagement, on the part of the teacher or pupils, from material and students, is part of the challenge of instruction in the theater history classroom.

Theater history can be a case study in the cross-disciplinary divide. Walter A. Davis (2007) writes that, "[t]he artist knows that the primary source of artistic creation derives from art's immanent critique of its own forms in terms of their inadequacy to the apprehension of new historical experiences" (80) (AQ: Emphasis added or in original?). Effective acting requires authenticity in a moment lived on the stage without reflexive evaluation until later. Effective history, however, is reflexive evaluation of completed human action(s). Like a theatrical performance, effective teaching and learning require moment-to-moment engagement with the process and the material. Learning history proceeds the same way, but doing history (as opposed to making) is more like the journalistic reflections of theatrical criticism.

It is probably a safe bet that most students in twenty-first century U.S. college and university theater departments want to do theater, rather than study its history. In the college theater history classroom, how do we make teaching authentic for undergraduate student populations that see themselves as practitioners of theater art, not scholars of the discipline as defined by the American academy? One way is to be reflexive as I witnessed my colleague 
Professor Knotts, as he asked students for immediate positive feedback on each other's model learning centers. Another important way is to avoid the disconnect between objectively assessable, and generally unperformable content, and subjective artistic interpretation. In an attempt to suture that disconnect, I assign students to make presentations about the plays we read, incorporating historical knowledge as if they are directing, designing, or acting a role in the play, thus giving students' creative impulse exercise while demanding they do research and present scholarly historical findings. This allows a combination of their creative and scholarly roles to actively engage with spectators (fellow students) in a learning activity.

Our four elements of authentic teaching can help cross the history/theater divide. However. Because theater is first and foremost an art, in an environment where education is treated as a commodity, with expectations of a quantifiable bang for the consumer's buck, teacher and student behavioral clichés, like those Hagen decried in professional acting, become a dangerous possibility. As greater pressure is brought onto teachers to standardize and use so-called "objective" assessment connected to Student Learning Outcomes (SLOs), the theater history classroom begins to lean toward reflexive history and away from the kind of doing actors practice in their training and performance. Theater history and praxis within the American academy are usually separate forms of knowledge. Although crossing the divide, within and across disciplines, is desirable, SLOs become barriers when the skill sets students are expected to gain are knowledge-based and discipline specific. Students, as creators/presenters, and I, as audience/assessor of their presentation projects, must feel ownership of the learning. Most of my students do so by making the project creative as theater, not as scholarship.

At the moment of creation, even in painting, for example, the past is important if we want to discuss the creative act or the created art, but even then, the history of art is only useful as a tool to guide a subjective opinion. In theater, a performance art like music and dance that lives only in the moment of performance, critical judgments are especially ephem- eral and open to dispute. How can SLOs be objectively assessable, when the object being discussed is so intangible and open to question? It would seem that applying objective criteria to a subjective form of knowledge invalidates the authenticity of both teaching and learning.

\section{Conclusions and Implications}

The knowledge fragmentation that Dewey found in unofficial educational settings can also be found, and with a vengeance, in institutions of higher learning. With their own sets of epistemological assumptions and research practices, each discipline produces and validates its own form of knowledge. While a diversity of knowledges is clearly a good thing overall, it can seem overwhelming to students. The question arises: how do the compartmentalized forms of knowledge situated within different academic disciplines articulate into a larger coherent package, a university education? As university instructors, the makers of this package, it is helpful to emerge from our own disciplinary home bases and actively expose ourselves to what is taking place in classrooms in other departments. By doing this we can better understand how the university appears to our students. This is essential if we are to assist our students in making the connections necessary to achieve Dewey's goal for formal education.

Beginning with our book group, our collaborative efforts have shown us how such cross-disciplinary exposure can assist us to be better guides for students. Observing authentic teaching and learning experiences across disciplines, and in turn creating relevant and authentic, and even cross-disciplinary, experiences for our own students, helps to better produce the "natural critical learning environment" that Bain says the "best college teachers" offer their students.

In examining our practice and crossdisciplinary experiences, our group identified a number of similarities amongst the challenges to our search for authenticity in our experience as first-year faculty. One primary challenge is recasting education as opportunity for students. Millenial students enter college with a certain sense of entitlement (Howe and Strauss 2000). They see college as just another task on their "life checklist." Our presence as educators (read: authority figures) in their lives is often viewed as an intrusion or an annoyance (Howe and Strauss 2000). To many of these students, receiving an education is seen as a matter of course, something that should, and typically has, come easily. In a culture of social promotion, and erring on the side of gold stickers and protecting the "fragile psyche" of students, K-12 educators pass students through the educational system, promoting many students beyond their abilities. Entrance scores for the last freshman class at our university place them in the seventieth percentile nationally. Meant neither as an indictment nor a sanction of K-12 educators (and taking into account the presence on our campus of first-generation college students and second language learners), these scores help to reveal the preparedness of today's average college student in our classes. Students believe that with scores in literacy and mathematics in the " $C$ " range, they are titled to a college education that will come as easily (be delivered as easily?) as that to which they have been accustomed, in their previous learning experiences.

Recasting learning as opportunity-as something to be earned, or at the very least, appreciated-required an investigation of our personal perspectives on this issue. We discovered that we all independently regarded education as a privilegea right and a necessity for the citizenry to continue advancing forward, but a privilege nonetheless. Education for each of us has been an experience of moving beyond the extrinsic reward of a grade or even the socially-approved extrinsic value a degree represented. Each of us is a lifelong learner who enjoys and values learning for learning's sake. We discovered our own authentic, intrinsic value in the learning process. Recasting education as opportunity for our students in this same way, inspiring them to perceive learning and their own education as a privilege, proved a collective challenge for us.

In addition to the challenges of making those connections for our students, the group also shared the challenge of differentiating the performance of our students. Recasting education as opportunity entails providing opportunities for students with diverse skill sets and levels of background 
preparation to perform at their best in our classes. Maintaining the interest of the most advanced students while engaging and raising the level of less skilled students is a constant challenge. Entailed within this challenge is another, which we call finding the optimal zone for learning. Our students represent the diverse class, ethnic, and linguistic backgrounds found in urban Los Angeles. Maintaining a cultural relevance, responding to a myriad of student needs, and balancing our own teaching and research responsibilities also continues to prove challenging.

Lastly is the challenge of authentic assessment. Each of us has struggled to develop learning tasks that require students to put their discipline-specific knowledge and methodological tools to work in real-world, meaningful contexts. We believe, with Bain (2004) and others, that the best assessment accounts for student performance of what they have learned in living, breathing work assignments rather than in hermetically-sealed, rote academic exercises.

Thus, one of the most important things that came out of our search for answers to these challenges was the collaboration in which we engaged. Our choice to work collaboratively, promoting self-reflexivity by exposure to other disciplines, attempts to incorporate reciprocity into class activities, encourage partial and positional truths, and cross-cultural perspectives has enlivened our teaching and institutional lives. "Authenticity" gained new relevance for each of us not only by broadening our set of teaching tools and our experiences of different classroom settings, but also by deepening engagement in our particular disciplinary contexts. Crossing the disciplinary divide and thinking about our four elements of authenticity gave us a means of buttressing both classroom practice and our personal growth as educators.

\section{NOTE}

1. The use of Deweyan methodology described in this paragraph is potentially useful at all education levels, and is in fact promoted throughout $\mathrm{K}-12$ public schools in Los Angeles by the University of California, Los Angeles History-Geography Project, for which I am a consultant.

\section{REFERENCES}

Auslander, P. 1999. Liveness: Performance in a mediatized culture. London: Routledge.

Bird, T. and C. Rossen. 2005. Providing authentic contexts for learning technology in teacher preparation. Journal of Technology and Teacher Education 13 (2): 211-31.

Brookfield, S. D. 2002. Using the lenses of critically reflective teaching in the community college classroom. New Directions for Community Colleges 118:3-38.

Brookfield, S. D. 2006. Authenticity and Power. New Directions for Adult and Continuing Education 111:5-16.

Cranton, P. and K. P. King. 2003. Transformative Learning as a Professional Development Goal. New Directions for Adult and Continuing Education 98: 31-37.

Cranton, P. 2006. Fostering authentic relationships in the transformative classroom. New Directions for Adult and Continuing Education 109:5-13.

Cranton, P., et.al. (AQ: Need other authors) 2006. Authenticity in Teaching. New Directions for Adult and Continuing Education. Jossey-Bass, San Francisco.

Daniel, J. and E. Guyton. 2003. Expanding our view of teaching and learning: Applying constructivist theory(s) to teacher education. Paper presented at the Annual Meeting of the American Association of Colleges of Teacher Education, New Orleans, LA.

Davis, W. A. 2007. Art and politic: Psychoanalysis, ideology, theater. London: Puto Press.

Desai, D. 2005. Places to go: Challenges to multicultural art education in a global economy. Studies in Art Education 46 (4): 293-308.

Dewey, J. 1944. Democracy and education: An introduction to the philosophy of education. New York: Free Press.

Diamond, E. 1997. Unmaking mimesis: Essays on feminism and theater. London: Routledge.

Dirkx, J. M. 2006. Authenticity and imagination. New Directions for Adult and Continuing Education 111:27-39.

Duncum, P. 2004. Visual culture isn't just visual: Multiliteracy, multimodality and meaning. Studies in Art Education 45 (3): 252-64.

Eisele, C. J. 1975. John Dewey and the immigrants. History of Education Quarterly 15 (1): 67-85.

Frego, K. A. 2006. Authenticity and relationships with students. New Directions for Adult and Continuing Education 111:41-50.

Gallavan, N. 2005. Helping teachers unpack their "Invisible Knapsacks." Journal of Multicultural Education 13 (1): 36.

Hagen, U. 1991. A challenge for the actor. New York: Scribner.

Howe, N. and W. Strauss. 2000. Milennials rising: The next great generation. Vintage: New York.

Huber, M. T. 2001. Balancing Acts: Designing Careers Around the Scholarship of Teaching. Change. 33 (4): 21-29.

Huber, M. T., P. Hutchings, G. Richard, R.
Miller, and M. Breen. 2007. Leading initiatives for integrative learning. Liberal Education 93 (2): 46-51.

Hunt, R. 2006. Institutional constraints on authenticity in teaching. New Directions for Adult and Continuing Education 111:5162.

Kartje, J. V. 1996. O mentor! My mentor! Peabody Journal of Education 71:114-25.

Katz, J. and M. Henry. 1988. Turning professors into teachers. New York: Macmillan.

Kornelson, L. 2006. Teaching With Presence. New Directions for Adult and Continuing Education 111:73-82.

Lin, L. 2006. Cultural dimensions of authenticity in teaching. New Directions for Adult and Continuing Education 111:63-72.

Mezirow, J. 1997. Transformative learning: Theory to practice. New Directions for Adult and Continuing Education 74:5-12.

Paulsen, M. B. and K. A. Feldman. 1995. Toward a reconceptualization of scholarship. Journal of Higher Education 66 (6): 615-40.

Quinlan, K. M. 1998. Promoting faculty learning about collaborative teaching. College Teaching 46 (1): 43-47.

Schechner, R. 1990. Magnitudes of performance. In By Means of Performance: Intercultural Studies of Theater and Ritual, ed .R. Schechner and W. Appel, 19-49. Cambridge: Cambridge University Press.

Stader, D. and F. Hill-Winstead. 2002. Portfolios, performance assessments, and sandards based learning in educational leadership. Paper presented at the Annual Meeting of the National Council of Professors of Educational Administration, Burlington, VT.

Sweeney, R. W. 2006. Visual culture of control. Studies in Art Education 47 (4): 294-307.

Taylor, P. G. 2004. (AQ: Says 2002 in the text) Hyperaesthetics: Making Sense of Our Technomediated World. Studies in Art Education 45 (4): 328-42.

TWIG. 1996. A feminist perspective on graduate student-advisor relationships. Feminist Teacher 10:17-25.

Williams, N. M., C. Connell, C. White, and J. Kemper. 2003. Real boats rock: A transdisciplinary approach for teacher preparation. Action in Teacher Education 24 (4): 95-102.

Wineburg, S. 2001. Historical thinking and other unnatural acts: Charting the future of teaching the past. Philadelphia: Temple University Press. 